Miller, D. A., S. Wu, and D. Kitzmiller, 2013: Spatial and temporal resolution considerations in evaluating and utilizing radar quantitative precipitation estimates. J. Operational Meteor., 1 (15), 168-184, doi: http://dx.doi.org/10.15191/nwajom. $\underline{2013.0115 .}$.

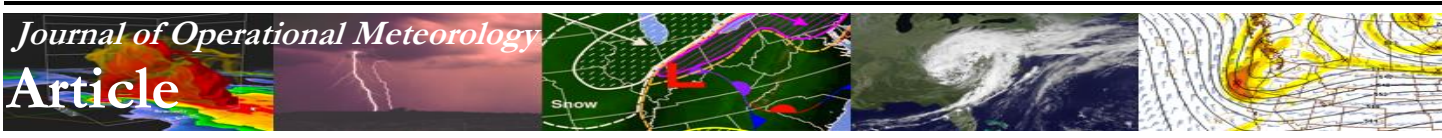

\title{
Spatial and Temporal Resolution Considerations in Evaluating and Utilizing Radar Quantitative Precipitation Estimates
}

\author{
DENNIS A. MILLER \\ NOAA/National Weather Service, Office of Hydrologic Development, Silver Spring, Maryland \\ SHAORONG WU \\ Wyle ST\&E Group and NCEP/Climate Prediction Center, College Park, Maryland \\ DAVID KITZMILLER \\ NOAA/National Weather Service, Office of Hydrologic Development, Silver Spring, Maryland
}

(Manuscript received 8 April 2013; review completed 6 August 2013)

\begin{abstract}
In recent years, Weather Surveillance Radar-1988 Doppler base data have become available at substantially finer spatial resolution-i.e., $0.25 \mathrm{~km} \times 0.5^{\circ}\left(0.25 \mathrm{~km} \times 1^{\circ}\right.$ for use in precipitation processing) versus the legacy $1 \mathrm{~km} \times 1^{\circ}$. Quantitative precipitation estimation (QPE) at this higher resolution may yield greater accuracy in the discretization of precipitation to delineated stream and river basins, in turn resulting in operational benefit in improved performance of hydrologic models and forecasting tools.

To assess this potential, 1-h radar QPEs were determined from two experimental, S-band radar systems across several spatial resolutions-starting with base reflectivity data at or near the newly available, fine resolution, and recombining them up to, and including, the legacy resolution. Next, 1-h QPE was calculated at these various resolutions (based on the traditional $Z-R$ relationship) and matched against 1-h rain gauge accumulations from dense gauge networks. After performing several steps of manual quality control, the dataset contained over 9500 warm-season gauge-radar pairs; these were assessed in various sub-groups and configurations (including stratification by precipitation intensity and range from the radar) and in simulated small stream basins. In various statistical analyses, however, the error differences between the fine- and legacy-resolutions were not statistically significant.

Several possible causes for this supposed counterintuitive result were investigated, including (1) increased sampling error/noisiness in smaller versus larger sample bins, (2) sub-beam factors acting on falling hydrometeors, and (3) the matter that temporal sampling frequencies employed operationally were not increased commensurately with the increase in spatial sampling resolution.
\end{abstract}

\section{Introduction}

\section{a. Background and motivation}

During the first nearly twenty years of operation of the Weather Surveillance Radar-1988 Doppler (WSR88D) system (a.k.a., NEXRAD), single-polarization base reflectivity data were provided from the radar data acquisition (RDA) unit to the radar products generator (RPG) computer at an effective spatial resolution of $1 \mathrm{~km} \times 1^{\circ}$ (Fulton et al. 1998). At the RPG, the legacy precipitation processing system (PPS) then derived quantitative precipitation estimation (QPE) products at this, or degraded, spatial resolutions [e.g., $\sim 4 \times 4 \mathrm{~km}^{2}$ for the digital precipitation data array (DPA) product and $2 \mathrm{~km} \times 1^{\circ}$ for the graphical products of 1-h precipitation (OHP) and storm-total precipitation (STP)]. The temporal resolution of the PPS QPE data was equivalent to that of the update period of the volume coverage pattern (VCP) or patterns in use during the precipitation eventtypically about $5 \mathrm{~min}$, down to about $4 \mathrm{~min}$ in some VCPs.

Corresponding author address: Dennis A. Miller, Office of Hydrologic Development, National Weather Service, 1325 East-West Highway, Silver Spring, MD 20910

E-mail: Dennis.Miller@noaa.gov 
Beginning with an enhancement introduced in the summer of 2008, base reflectivity data became available from the RDA to the RPG at eight times higher spatial resolution (i.e., $0.25 \mathrm{~km} \times 0.5^{\circ}$; termed super-resolution by Brown et al. 2005). However, no operational PPS products were upgraded initially to this finer resolution, as the base reflectivity data were recombined in both the azimuthal and radial directions (i.e., $1 \mathrm{~km} \times 1^{\circ}$ ) prior to processing by the PPS. Then, beginning in 2011 with the upgrade of the WSR-88D system to dual-polarization (DP) capability (Ryzhkov et al. 2005), DP-based QPE products (DP-QPE) became available from base data recombined only in the azimuthal direction (i.e., $0.25 \mathrm{~km} \times 1^{\circ}$ ), which is four times higher spatial resolution than the single polar-based PPS products (that still are available).

These developments lead to consideration of how the availability of substantially higher spatialresolution, radar-based QPE products might impact operational hydrologic models and forecasting tools. Intuitively, it may seem that higher resolution products - which more specifically, and assumedly more accurately, capture the precipitation characteristics at any particular location-would allow for greater refinement in the distribution of precipitation to delineated stream and river basins, subsequently resulting in improved accuracy in hydrologic forecasts. However, several factors may work counter to this presumed outcome. Base radar fields, such as reflectivity, have higher variances and are noisier when originally determined over smaller sampling volumes. Also, any relationship between enhanced resolution in the sampling of hydrometeors aloft and improved accuracy in the estimation of precipitation-perhaps several minutes later-at the ground below, as measured by verification devices such as rain gauges or disdrometers, may not be as clear as presumed. Sub-beam factors that could cause gauge-radar $(\mathrm{G}-\mathrm{R})$ discrepancies, such as advection, evaporation, and hydrometeor interactions might, on the whole, overwhelm any statistical differences that may have been present owing to sampling in the same location but at a different spatial resolution. For example, if one employs the WSR-88D assumptions for index of refraction (1.21) and mean radius of the earth $(6371 \mathrm{~km})$, the center of a $0.5^{\circ}$ beam would be $\sim 9.08 \mathrm{kft}$ above ground level (AGL) at $150 \mathrm{~km}$ range. Assuming a terminal fall velocity of $\sim 9 \mathrm{~m} \mathrm{~s}^{-1}$ for a medium-sized raindrop $(\sim 5 \mathrm{~mm}$ diameter; Corbert 1974), a drop falling from that height would take $\sim 5$ min to reach the ground, and if an average horizontal wind of $10 \mathrm{~m} \mathrm{~s}^{-1}$ were acting upon it, it would be advected laterally $\sim 3 \mathrm{~km}$ during its descent. So, even if the radar were to detect precipitation aloft well, the likelihood that a surface-based gauge-presumed directly below the precipitation-would accurately reflect that estimate would be substantially reduced.

Furthermore, there were no changes in WSR-88D temporal surveillance strategies commensurate with the upgrade in spatial resolution; hence, sampling of individual locations in the surrounding atmosphere remained no more frequent than once every 4-5 min. The corresponding total dwell time of $<1 \mathrm{sec}^{-1}$ over any one point alone could limit the effectiveness of any enhancement in spatial resolution.

Because the costs involved in supplying enhanced resolution QPE to the National Weather Service (NWS) hydrologic models and forecasting tools could be substantial - owing to the much larger data volumes and bandwidths having to be accommodated-the potential benefits of these higher spatial-resolution QPE data should be assessed. Because there was a long history of utilization of single-polarization-based QPE in NWS operations at the time this study began, and because DP-QPEs were newly available and some issues were still being worked out, all QPEs in this analysis were determined from the single-polarization methodology employed in the WSR-88D legacy PPS that is still in operational use today. And because of our interest in implications for NWS operations, all radar estimates were derived from base data sampled at the S-band $(\sim 10 \mathrm{~cm})$ wavelength utilized by the WSR-88D national network.

\section{b. Brief overview}

The content of this paper is as follows: section 2 reviews earlier studies; section 3 contains a description of the study methodology; section 4 describes how we developed our G-R datasets including quality control (QC) measures applied; section 5 contains experimental results for the various situations and configurations of data analyzed, as well as some assessment of those results; section 6 provides an assessment of the statistical significance of the differences in the errors of the radar QPE, from the relatively fine to the relatively coarse spatial resolutions; section 6 also explores-from a theoretical perspective with practical examples - what limitations there may be in achieving improved accuracy in operational precipitation accumulation estimates from just an increase in the spatial resolution 
of available base data, without a commensurate increase in the temporal resolution of those data; and section 7 contains a summary of findings.

\section{Previous studies}

Even though numerous studies on radar QPE errors and correction methods have been published, only a portion of them deal directly with questions of variable horizontal aggregation of the radar observations. These include those of Habib and Krajewski (2002) and Gebremichael and Krajewski (2004); their primary focus was to assess radar-rainfall error characteristics as a function of spatial scale by comparison with correlation functions derived from high-density rain gauge networks. More recently, Knox and Anagnostou (2009) reported on the effects of interpolating high-resolution QPEs from an X-band radar unit to grids with mesh lengths varying from 300-5000 m, regarding grid-to-point gauge rainfall correlations. They reported that grid mesh length had only a minor effect on correlation statistics such as rainfall detection and root mean square error (RMSE) for accumulation periods from 15 to $60 \mathrm{~min}$, though some improvement was evident for the finer grid mesh lengths. Potentially important differences between this study and ours are that all G-R correlation estimates were based on rain gauges less than $25 \mathrm{~km}$ from the radar in theirs, and the scanning frequency was 1 min-much less than the 4-5 min necessitated by general weather surveillance as carried out by the WSR-88D. Also, the Knox and Anagnostou study was based on light-to-moderate rainfall events, whereas ours contains numerous cases of rainfall rates $>12.5$ $\mathrm{mm} \mathrm{h}^{-1}$.

In a study somewhat analogous to our own, Seo and Krajewski (2010) employed super-resolution data collected from two WSR-88D radars in Iowa during the mild-to-warm seasons of 2008-2009, recombined those data over five distinct spatial scales $(0.5,1,2,4$, and $8 \mathrm{~km}$ ) and two temporal periods (15 min and $1 \mathrm{~h}$ ), and performed error variance analyses of radarestimated precipitation at those scales/periods against high-density rain gauge reports. They found that recombination reduced relative error standard deviations significantly (by 2- to 3-fold from the finest to the coarsest spatial resolution) at each temporal scale. However, they recombined their data in both the azimuthal and radial directions into various scaled versions of the Cartesian hydrologic rainfall analysis project (HRAP) grid projection, starting from true super-resolution at $0.25 \mathrm{~km} \times 0.5^{\circ}$, whereas we started with base data already recombined azimuthally to $1^{\circ}$ and recombine it further only in the radial direction. In another study comparing super-resolution to legacy, Torres and Curtis (2006) found that halving the azimuthal resolution from $1^{\circ}$ to $0.5^{\circ}$ increased estimation errors by a factor of about 2.5 , which is attributable to the reduced number of radar pulses contributing to the sample. This is not a factor in changing the sampling size in just the radial direction as the number of pulses remains the same; only the duration of integration of the returned signals changes. Hence, in our study, we would not expect to experience increases in base data estimation error variance with recombination to the same extent as in the Seo and Krajewski (2010) study.

Our study specifically endeavors to determine whether there may be a benefit to NWS hydrologic models and forecasts from the use of the new QPE at spatial resolutions below $1 \mathrm{~km}$. This is particularly relevant as the NWS moves towards higher resolution hydrologic models.

\section{Research approach and methodology}

The methodology employed in this study is to (1) compute 1-h, single-polarization, S-band-based, QPEs for a set of discrete spatial resolutions, (2) match these against collocated, 1-h rain gauge reports from sufficiently dense networks, and, after undertaking several QC measures, (3) determine statistical results for the resultant set of $\mathrm{G}-\mathrm{R}$ pairs. The discrete resolutions range from approximately that now used in DP-QPE products $\left(0.25 \mathrm{~km} \times 1^{\circ}\right)$ to approximately that of the legacy PPS $\left(1 \mathrm{~km} \times 1^{\circ}\right)$, with the successively coarser-resolution radar QPE fields determined from the finest resolution base data available by recombination of those data in the radial direction. Comparison of the radar QPE at the various resolutions against the gauges is undertaken in three phases of analysis, each involving a distinct configuration of the rain gauges within the radar umbrella, as explained below. Statistics for each combination of radar resolution against rain gauge configuration are then analyzed to assess the hypothesis that enhanced resolution radar data will yield greater accuracy in ground-based QPEs.

We have focused this study on the 1-h accumulation period because, while both shorter and longer accumulation periods are of interest in different aspects of hydrologic modeling, the $1-\mathrm{h}$ period is 
crucial to multiple aspects of operational hydrologic prediction, such as $\mathrm{G}-\mathrm{R}$ bias correction (Kitzmiller et al. 2013). Furthermore, studies such as Wang and Wolff (2010) demonstrate that correlations between gauge and radar QPE decrease as accumulation periods become shorter, which suggests that interpretation of results would become more complicated if a shorter interval were studied.

In order to conduct this study, good datasets of both high-resolution reflectivity data from an S-band radar (WSR-88D or similar) and rain gauge reports from dense rain gauge networks, gathered simultaneously, had to be available. At the time our study began, the experimental WSR-88D at the National Severe Storms Laboratory (NSSL) in Norman, Oklahoma (KOUN), had been collecting super-resolution, dual-polarized, base moments for a few years prior, and was selected as one of our data sources. Coincident gauge reports were provided by the Oklahoma Climatological Survey Mesonet, with over 750 candidate $\mathrm{G}-\mathrm{R}$ pairs found during the warm seasons of 2004 and 2005.

However, because of the somewhat limited number of these G-R pairs, we selected as the primary radar data source the National Center for Atmospheric Research (NCAR)'s S-band, DP, Doppler radar (known as S-Pol) while it was located in the vicinity of Melbourne, Florida, during the summer of 1998 (Brandes et al. 1999). This radar returned moments with range-azimuth dimensions of $150 \mathrm{~m} \times \sim 0.91^{\circ}$ (which we averaged to $1^{\circ}$ ). VCPs varied, but the predominant periodicity over which scans were collected was $\sim 5 \mathrm{~min}$ (i.e., comparable to that of the operational WSR-88D when precipitation is present). The S-Pol deployment was coincident with that of the National Aeronautics and Space Administration's dense (as closely spaced as $1 \mathrm{~km}$ ) Tropical Rainfall Measurement Mission-Ground Validation (TRMM$\mathrm{GV}$ ) rain gauge network (Gebremichael and Krajewski 2004). This simultaneous deployment was designed for the Texas-Florida Underflights (TEFLUN-B) experiment (Habib and Krajewski 2002). Over 8900 suitable G-R pairs were found for our study within a $171-\mathrm{km}$ umbrella of the S-Pol radar during the period 20 July-29 September 1998. Hourly rainfall estimates were determined at each of the following levels of aggregation: $150,300,450,600,750$, and $900 \mathrm{~m}$.

These hourly radar QPEs were then compared in three phases of analysis with: 1) all individual, hourly gauge reports under the entire radar umbrella; 2) clusters (subsets) of more densely packed gauges covering areas $<20 \mathrm{~km}^{2}$ (representing multiple, small basins of theoretical stream networks); and 3) gaugeestimated, mean-areal precipitation (MAP) within the same clusters, over areas $<20 \mathrm{~km}^{2}$. Note that the first analysis phase was applied to both the Florida and KOUN/Oklahoma Mesonet (2004-2005) datasets (the latter at 250, 500, 750, and $1000 \mathrm{~m}$ ) while the second and third phases were conducted on just the Florida dataset. The discussions in sections 4-7 (below) are focused primarily on the Florida dataset.

Before each of these analysis phases was conducted, we removed the long-term bias during the full data collection period by adjusting all the radar accumulations using a multiplicative bias-correction, defined as the ratio of gauge-mean to radar-mean accumulations among all qualifying pairs across all resolutions in the dataset (i.e., the inverse of the radar bias itself). Then, at each spatial resolution for the respective situations mentioned above, we determined the following statistics: (adjusted) mean radar accumulation; radar/gauge ratio (R/G); correlation coefficient (CC); mean absolute error (MAE); standard deviation (SD); and RMSE.

\section{Data processing}

\section{a) Development of the $G-R$ pair datasets}

Both the rain gauge reports and the radar-based QPEs were assembled for "clock hourly" blocks (i.e., beginning/ending at the top of an hour). This also matched the accumulation period of WSR-88D DPA products [i.e., those from the nearby Melbourne (KMLB) radar for the Florida study]. In order for a set of G-R pairs for a particular hour to be included in the sample for one of the respective analysis phases, either the gauge report or the radar estimate at just one of the spatial resolutions (six for Florida, four for Oklahoma) had to be nonzero. Note that by this methodology there was no preference toward either the gauge or radar values. In total, 8902 nonzero (hourly) G-R pair sets were found for the principal (Florida) dataset over 96 raining hours, while 754 such pair sets were found for the auxiliary (Oklahoma) dataset.

\section{b) Rain gauge data and QC for the Florida dataset}

Rain gauge data for the primary dataset were from the standard data product 2A56 of the TRMM-GV program, collected from the TRMM Satellite Validation Office (SVO)'s website (trmm-fc.gsfc. nasa.gov/trmm_gv). Data product 2A56 is a 1-min 
average rain-gauge rain rate, interpolated from tipping bucket rain gauge data. For every working rain gauge, rain rates were reported in $\mathrm{mm} \mathrm{h}^{-1}$ for every minute in which the gauge registered measurable rainfall; these minute-by-minute accumulations were summed to yield the hourly amounts.

The distribution of gauges within a radius of 171 $\mathrm{km}$ from the S-Pol unit in Melbourne, Florida, is shown in Fig. 1. The figure shows only the 125 gauges that were retained after QC procedures (explained below) were applied. Because our study dealt with the ability of the radar to represent small-scale spatial variability in rainfall, attention also was focused on several high-density gauge subnetworks (Fig. 1), with details of two such networks appearing in Fig. 2.

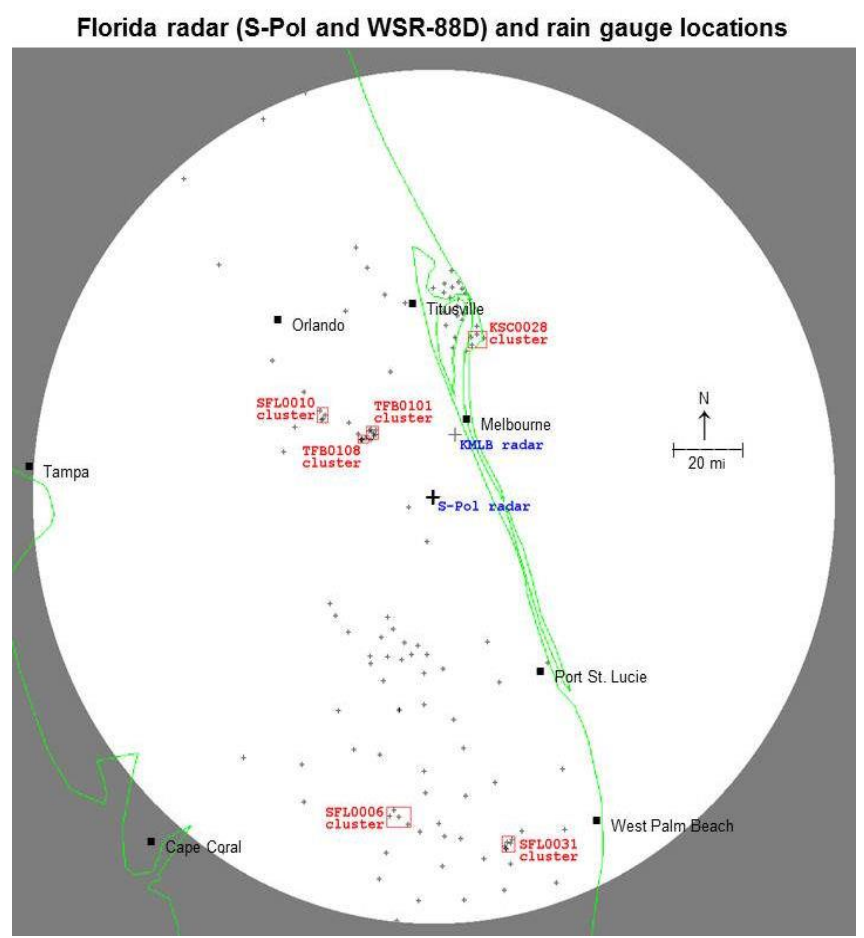

Figure 1. Distribution of gauge sites (small crosses) relative to SPol radar site (large cross at center). Six subnetworks or "clusters" of closely located gauges are shown in red. The white circle indicates a radius of $171 \mathrm{~km}$. WSR-88D Melbourne (KMLB) radar also shown. Click image for an external version; this applies to all figures hereafter.

Several QC steps were performed before any given gauge's data would be used in the statistical analysis. The great-circle distance and azimuth from KMLB to each of the candidate gauges were computed based on their latitude/longitude, and the results compared to the analogous information provided in the header lines of the individual TRMM-GV gauge data
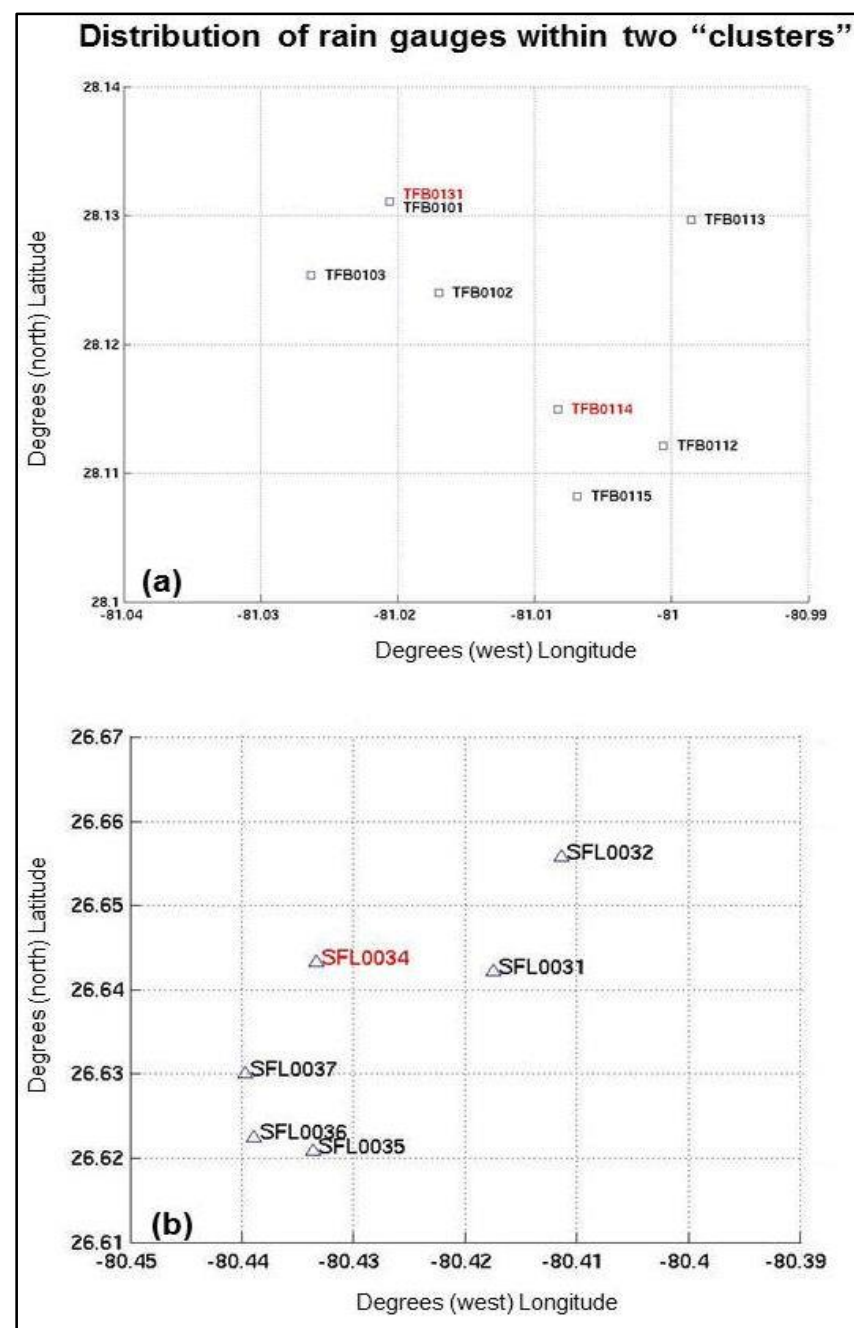

Figure 2. Distribution of the gauges within two of the clusters that are shown in Fig. 1: (a) TFB0101 and (b) SFL0031. Latitude and longitude are indicated; gauge sites highlighted in red had suspect values and were not included in the analysis. The distance between lines of $0.01^{\circ}$ latitude are $\sim 1.11 \mathrm{~km}$ and $0.01^{\circ}$ longitude are $\sim 0.98$ $\mathrm{km}$.

files. In instances where the distances differed by more than 100 meters, the gauges were discarded.

In a second, subjective QC step, rain rates from gauges located near one another (i.e., in the same or adjacent $\sim 4 \times 4 \mathrm{~km}^{2}$ HRAP grid boxes) were plotted simultaneously, in mirror-image fashion (one above and one below the horizontal axis), for the raining hours comprising the dataset, numbered successively. If periods of sharp discrepancy were observed, both traces would be compared against the trace of the DPA 1-h rainfall product for the corresponding hours from the WSR-88D KMLB radar in the same HRAP grid box. For example, among the gauges comprising the TFB0101 cluster, shown in Fig. 2, TFB0112 and 
TFB0115 mirror each other closely during the first portion of the period 20 July 1998-29 September 1998 , but diverge substantially thereafter, with the reports from TFB0115 appearing to have been shifted about 39 (sample) hours earlier. In Figs. 3 and 4, the two gauges are compared, respectively, against the corresponding DPA time series. It is evident that while TFB0112 matches the DPA product very well, TFB0115 only does so during the early hours, then reveals big differences after about time index 35 . Hence, the latter portion of TFB0115, after 1400 UTC 4 September 1998, was removed from our dataset.

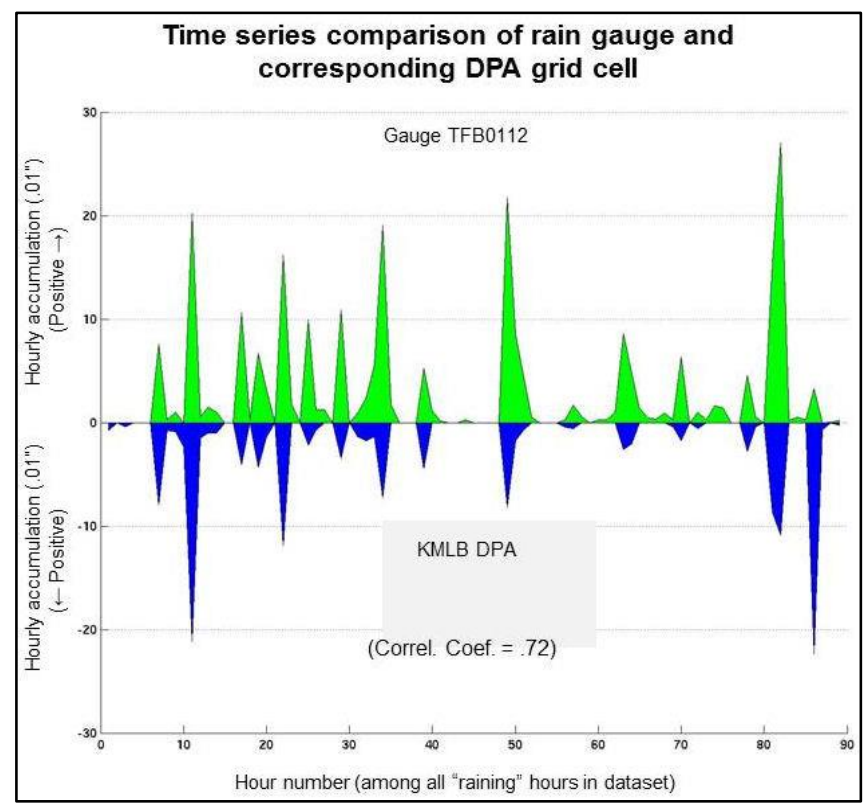

Figure 3. Time series of hourly rainfall from rain gauge site TFB0112 (top, green) and KMLB DPA products (bottom, blue). Horizontal axis is the hour number among all raining hours in central Florida during the summer of 1998 that comprised the dataset. Vertical axis is the hourly rainfall in 0.01 in; values below the horizontal axis are positive, though displayed in the opposite sense.

Also, no simple means of distinguishing between missing data and true "no rain" was provided in the gauge reports. In instances when gaps appeared, these were assumed to indicate no rain unless they were prolonged (i.e., > $6 \mathrm{~h}$ ) and/or occurred at the end of the TEFLUN-B experimental period, in which case they were assumed to reflect missing periods.

In one additional, subjective QC step, conducted because the S-Pol base reflectivity data were not subjected to the types of automated clutter and anomalous propagation procedures as the WSR-88D data, the gauge reports were examined against the collocated S-Pol returns for evidence of ground clutter.

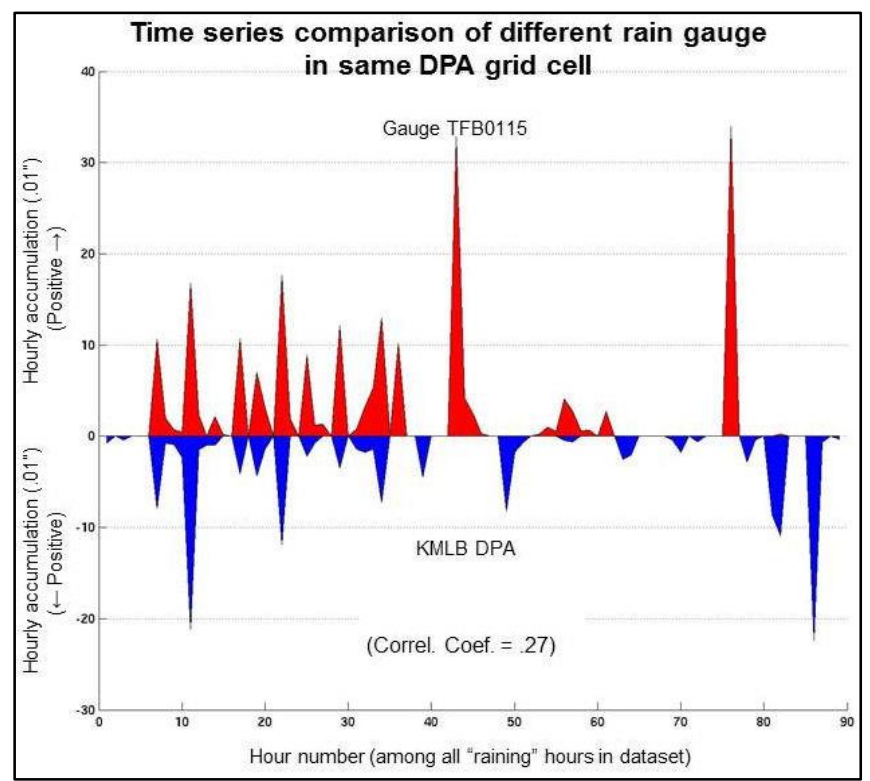

Figure 4. As in Fig. 3, except the gauge site is TFB0115 (top, red).

If contamination was determined to be present at even one of the radar resolutions, the $\mathrm{G}-\mathrm{R}$ pairs at all resolutions for that set (i.e., for that hour) were discarded.

After all QC procedures were applied, 125 gauge sites were retained in part or in full, as seen in Fig. 1. Based on these, a long-term bias correction of 1.36 was then determined and applied to all the S-Pol radar estimates, which on average were somewhat low.

\section{c) Radar data-1-h rainfall estimates from S-Pol}

Radar data for the primary dataset were collected by NCAR's S-Pol system in the summer of 1998 in the vicinity of Melbourne, Florida (see above for details). Rainfall estimates from the S-Pol were calculated using an independently implemented, in-house, QPE algorithm based closely on the WSR-88D PPS. In our algorithm, S-Pol data from up to 13 volume scans were used to calculate the 1-h rainfall estimates. Time intervals between these volume scans were approximately $5 \mathrm{~min}$, corresponding well with WSR88D scanning strategies. Reflectivity fields from the $0.5^{\circ}$ elevation scan were used to calculate the rainfall rates by employing the default (i.e., convective) $\mathrm{Z}-\mathrm{R}$ relationship from NEXRAD [i.e., $Z=\mathrm{aR}^{\mathrm{b}}$; where $\mathrm{Z}=$ backscattered reflectivity power $\left(\mathrm{mm}^{6} \mathrm{~m}^{-3}\right), \mathrm{R}=$ rainfall rate $\left(\mathrm{mm} \mathrm{h}^{-1}\right), a=300$, and $\left.\mathrm{b}=1.4\right]$. To determine reflectivities at the aggregated 300-900-m resolutions, the $\mathrm{Z}$ values from two to six, respectively, of the basic 150-m sample bins were averaged along the radial direction. 
Once rainfall rates were calculated at each of these resolutions, the incoming radar beams were mapped (by weight, based on their central azimuth angles and amount of overlap) into single or adjacent slots of a fixed polar grid with azimuthal resolution of $1^{\circ}$. After all incoming radials were processed for a volume scan, the final rainfall rates on the $1^{\circ}$ fixed grid were determined by taking the weighted sum of rates mapped to each grid slot and dividing by the sum of the overlap weights. The rates determined in this manner at the discrete times of radar sampling were then linearly averaged across the intervals between each successive pair-set (or between the top of the clock hour and the first sample time within the hour, or the last sample time and the end of the clock hour). The accumulations in these intervals were then summed to determine the 1-h rainfall estimates.

\section{d) The Oklahoma datasets}

For the Oklahoma portion of the study, we repeated the fundamental analysis described above, though here with super-resolution data (in the radial direction, only) collected by KOUN during the warm seasons of 2004 and 2005, matched with hourly gauge reports from the Oklahoma Climate Survey Mesonet (McPherson et al. 2007). That mesonet contains numerous gauges beginning $35 \mathrm{~km}$ from the KOUN radar; we used 103 of them out to a range of $250 \mathrm{~km}$, their average distance being $142 \mathrm{~km}$. We identified no suspect gauge reports within this dataset.

We prepared 1-h rainfall estimates from horizontally polarized reflectivity measurements at the original $0.25 \mathrm{~km} \times 1^{\circ}$ resolution and from reflectivity aggregated in the radial direction, from $250 \mathrm{~m}$ to 500 , 750 , and $1000 \mathrm{~m}$ - the last corresponding to the resolution of the PPS digital hybrid-scan reflectivity product that is used to feed NWS's operational applications such as high-resolution precipitation estimator and high-resolution precipitation nowcaster. Although no additional quality control was attempted, these reflectivity data were filtered by an early version of the polarimetric hydrometeor classification algorithm (Park et al. 2009), which appeared to be effective at reducing returns from biota and ground clutter. An overall bias-correction factor of 0.48 was determined and applied to the radar estimates to correct their consistent high bias relative to the gauge reports. Note that while the KOUN radar estimates may have been too high and the S-Pol radar estimates too low, the uniform application of a mean-field, multiplicative bias correction will have no impact on the relative correlations and error measures across the range of spatial resolutions - in either dataset.

\section{Results and findings}

\section{a) Florida (S-Pol-TRMM-GV) results}

\section{1) OVERVIEW OF WEATHER DURING THE TEST PERIOD}

The weather situation during the course of the TEFLUN-B experiment (20 July-29 September 1998) was typical of late summer over Florida, with some intense local rainfall and some cases with mesoscale organization of precipitation features. Data from 27 days were utilized. Overall, approximately $37 \%$ of the hourly gauge reports indicated rainfall $\geq 0.25 \mathrm{~mm}, 11 \%$ had $\geq 2.5 \mathrm{~mm}$, and about $0.7 \%$ had $\geq 25 \mathrm{~mm}$.

Figure 5 shows some typical reflectivity patterns during the period. The images are of reflectivity from the $0.5^{\circ}$ elevation during afternoons. Over the Florida peninsula, both scattered multicellular (as seen in Fig. $5 \mathrm{~b}$ ) and organized mesoscale (Fig. 5c, d) precipitation were evident.

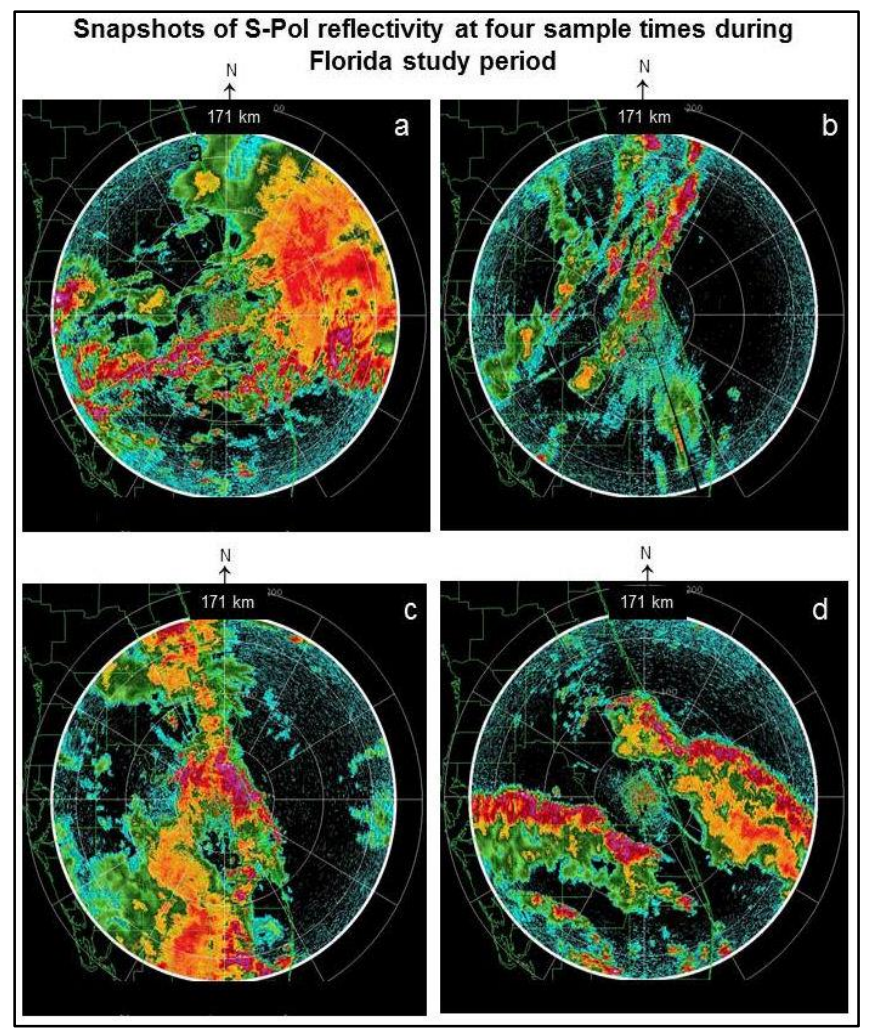

Figure 5. Radar reflectivity from the $0.5^{\circ}$ elevation during 1998 at (a) 1801 UTC 20 August, (b) 1900 UTC 3 September, (c) 2100 UTC 17 September, and (d) 2100 UTC 25 September. 


\section{2) Phase 1-ALl G-R PAIRS CONSIDERED}

In this phase, conducted to test the effect of spatial aggregation of radar data on $\mathrm{G}-\mathrm{R}$ correlation in general, correlation and error statistics were calculated first for all G-R pairs under the radar umbrella, then for subsets of those pairs falling within discrete range bands (i.e., near $=0-67 \mathrm{~km}$; middle $=67-106 \mathrm{~km}$; far $=106-171 \mathrm{~km})$. Note that a $1^{\circ}$-wide beam spans approximately $1 \mathrm{~km}$ in height and width at $57 \mathrm{~km}$ from the radar, $2 \mathrm{~km}$ at $114 \mathrm{~km}$, and $3 \mathrm{~km}$ at $171 \mathrm{~km}$. Figure 6 provides a schematic representation of the rain gauge and radar sample bin aggregations used. Results for the various $\mathrm{G}-\mathrm{R}$ statistical measures, all together and in each range grouping, are shown in Table 1.

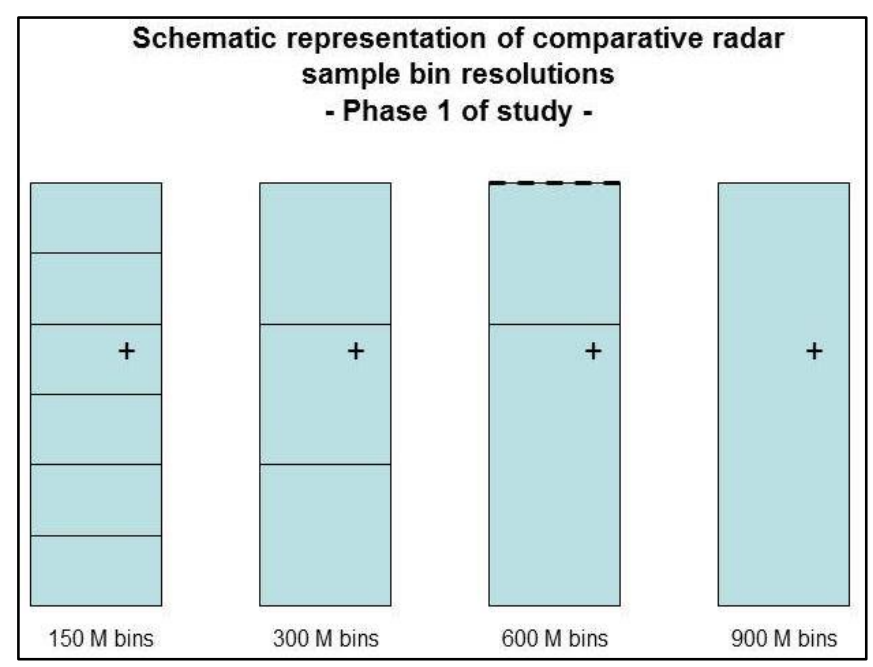

Figure 6. Schematic representation of radar sample bin QPE aggregations for phase 1 of the Florida S-Pol study: G-R comparisons. Note that varying radar areas are matched against the same gauge point (location indicated by + ); aggregations are based on distance from radar, not centered upon gauges.

It is apparent for each statistical measure in each grouping that the results across all resolutions are quite similar, particularly when all G-R pairs are considered together (top part of Table 1). From the nearly identical results in the standard deviation fields it does not appear that the matter of base data being inherently noisier when determined in smaller versus larger sample bins had any bearing on our outcomes. When stratified by distance, a minor tendency toward better statistical results (i.e., higher CC and lower MAE, SD, and RMSE) at the finer end of the spatial resolutions is seen in the near-range band and, to a lesser degree, in the middle-range band, while a minor tendency toward better statistical results at the coarser resolutions is seen in the far-range band. Before we attempt to postulate any physical explanations for these small differences, however, we will conduct an assessment of whether they qualify as statistically significant (though we defer that analysis until after the discussions of phases 2 and 3 ).

\section{3) Phase 2-G-R CORRELATION IN SMALL GAUGE NETWORKS}

The second phase of the experiment was designed to determine if spatial aggregation of the radar data had an effect on representation of the spatial rainfall pattern, but not necessarily the absolute rainfall amount. Figure 7 provides a schematic representation of the rain gauge and radar sample bin aggregations used in this phase. This question is important because some NWS operational practices are based on the assumption that the radar can properly depict sharp spatial gradients in rainfall and differentiate between rain amounts over adjacent, small stream basins. When the radar data are aggregated over larger volumes, some precipitation from outside the bounds of the basin (or local gauge network) will begin to be included, and the radar representation of some spatial gradients could be degraded.

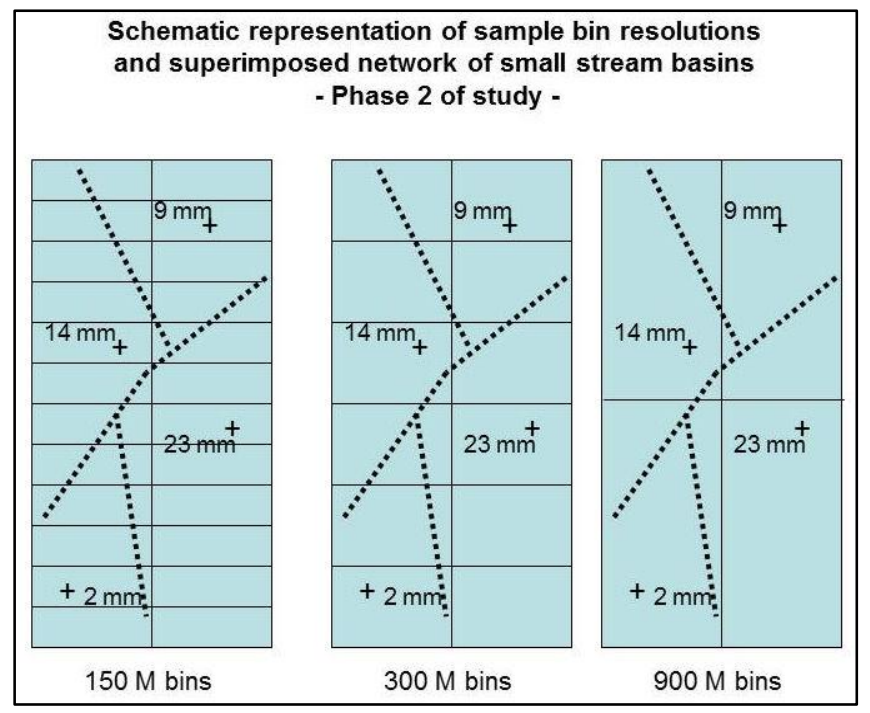

Figure 7. Schematic representation of radar sample bin QPE aggregations for phase 2 of the Florida S-Pol study: simulated network of small stream basins (delineated by dashed lines) covered by closely spaced gauge network. Note that different radar sample bins (whose centers fall in each theoretical basin) contribute to QPE of those basins, depending on radar resolution.

Therefore, we examined the correlation between 1-h radar and gauge estimates within small subnetworks or clusters of 4-7 closely located gauges, 
Table 1. Statistics (gauge-radar correlation coefficients, mean absolute errors, standard deviations and root-mean-squared errors), ordered by spatial resolution, for Florida S-Pol radar data. All G-R pairs in the radar coverage area are considered together, then stratified by range from the radar. Gauge or radar value must be nonzero (i.e., $\geq 0.1 \mathrm{~mm}$ ) for any G-R pair to qualify.

\begin{tabular}{|c|c|c|c|c|c|c|}
\hline \multirow[t]{2}{*}{ All ranges together } & \multicolumn{4}{|c|}{8902 R/G-data-pairs } & \multirow[b]{2}{*}{$\begin{array}{c}\text { SD } \\
(\mathrm{mm})\end{array}$} & \multirow[b]{2}{*}{$\begin{array}{c}\text { RMSE } \\
(\mathrm{mm})\end{array}$} \\
\hline & $\begin{array}{l}\text { Mean } \\
(\mathrm{mm})\end{array}$ & R/G Ratio & $\mathrm{CC}$ & MAE (mm) & & \\
\hline \multicolumn{7}{|l|}{ Gauge 1.77} \\
\hline 150m-radar & 1.74 & 0.98 & 0.81 & 1.04 & 2.93 & 2.93 \\
\hline 300m-radar & 1.76 & 0.99 & 0.81 & 1.05 & 2.92 & 2.92 \\
\hline 450m-radar & 1.76 & 1.00 & 0.81 & 1.05 & 2.93 & 2.93 \\
\hline 600m-radar & 1.78 & 1.01 & 0.82 & 1.05 & 2.91 & 2.91 \\
\hline 750m-radar & 1.78 & 1.01 & 0.81 & 1.05 & 2.92 & 2.92 \\
\hline 900m-radar & 1.79 & 1.01 & 0.81 & 1.05 & 2.92 & 2.92 \\
\hline \multirow[t]{2}{*}{ range $0-67 \mathrm{~km}$} & \multicolumn{4}{|c|}{3431 R/G-data-pairs } & & \\
\hline & $\begin{array}{l}\text { Mean } \\
(\mathrm{mm})\end{array}$ & R/G Ratio & $\mathrm{CC}$ & $\begin{array}{l}\text { MAE } \\
(\mathrm{mm})\end{array}$ & $\begin{array}{c}\mathrm{SD} \\
(\mathrm{mm})\end{array}$ & $\begin{array}{l}\text { RMSE } \\
(\mathrm{mm})\end{array}$ \\
\hline \multicolumn{7}{|l|}{ Gauge 1.56} \\
\hline 150m-radar & 1.59 & 1.02 & 0.81 & 0.91 & 2.82 & 2.82 \\
\hline 300m-radar & 1.63 & 1.05 & 0.81 & 0.94 & 2.83 & 2.83 \\
\hline 450m-radar & 1.62 & 1.04 & 0.81 & 0.92 & 2.83 & 2.83 \\
\hline 600m-radar & 1.66 & 1.07 & 0.81 & 0.95 & 2.83 & 2.83 \\
\hline 750m-radar & 1.65 & 1.06 & 0.81 & 0.93 & 2.81 & 2.82 \\
\hline 900m-radar & 1.67 & 1.07 & 0.80 & 0.94 & 2.85 & 2.85 \\
\hline \multirow[t]{2}{*}{ range $67-106 \mathrm{~km}$} & \multicolumn{4}{|c|}{2990 R/G-data-pairs } & & \\
\hline & $\begin{array}{l}\text { Mean } \\
(\mathrm{mm})\end{array}$ & R/G Ratio & $\mathrm{CC}$ & $\begin{array}{l}\text { MAE } \\
(\mathrm{mm})\end{array}$ & $\begin{array}{c}\mathrm{SD} \\
(\mathrm{mm})\end{array}$ & $\begin{array}{l}\text { RMSE } \\
(\mathrm{mm})\end{array}$ \\
\hline \multicolumn{7}{|l|}{ Gauge 1.76 } \\
\hline 150m-radar & 1.64 & 0.93 & 0.85 & 0.95 & 2.93 & 2.93 \\
\hline $300 \mathrm{~m}$-radar & 1.65 & 0.94 & 0.85 & 0.95 & 2.91 & 2.91 \\
\hline 450m-radar & 1.65 & 0.94 & 0.85 & 0.95 & 2.92 & 2.93 \\
\hline 600m-radar & 1.68 & 0.96 & 0.85 & 0.96 & 2.93 & 2.93 \\
\hline 750m-radar & 1.68 & 0.96 & 0.84 & 0.97 & 2.95 & 2.95 \\
\hline 900m-radar & 1.69 & 0.96 & 0.84 & 0.97 & 2.94 & 2.94 \\
\hline \multirow[t]{2}{*}{ range $106-171 \mathrm{~km}$} & \multicolumn{4}{|c|}{2481 R/G-data-pairs } & & \\
\hline & $\begin{array}{l}\text { Mean } \\
(\mathrm{mm})\end{array}$ & R/G Ratio & $\mathrm{CC}$ & $\begin{array}{l}\text { MAE } \\
(\mathrm{mm})\end{array}$ & $\begin{array}{c}\mathrm{SD} \\
(\mathrm{mm})\end{array}$ & $\begin{array}{l}\text { RMSE } \\
(\mathrm{mm})\end{array}$ \\
\hline \multicolumn{7}{|l|}{ Gauge 2.08} \\
\hline 150m-radar & 2.06 & 0.99 & 0.78 & 1.33 & 3.07 & 3.07 \\
\hline 300m-radar & 2.07 & 0.99 & 0.78 & 1.32 & 3.05 & 3.05 \\
\hline 450m-radar & 2.08 & 1.00 & 0.78 & 1.34 & 3.05 & 3.05 \\
\hline 600m-radar & 2.07 & 1.00 & 0.79 & 1.31 & 3.01 & 3.01 \\
\hline 750m-radar & 2.08 & 1.00 & 0.79 & 1.33 & 3.03 & 3.03 \\
\hline 900m-radar & 2.09 & 1.00 & 0.79 & 1.31 & 2.99 & 2.99 \\
\hline
\end{tabular}

occupying only a few tens of $\mathrm{km}^{2}$. Six such clusters were identified (refer to Fig. 1). An individual hour's information was included in a cluster's dataset when the difference between the largest and smallest 1-h radar report within the cluster was $\geq 2.5 \mathrm{~mm}$ to assure that some appreciable variability existed in the smallscale rainfall pattern. All of the gauge and radar estimates for any such hour were ranked by order of amount, and then the respective rank positions were correlated.

Shown in Table 2 are the mean correlations as a function of aggregation distance (150-900 m) over all qualifying hours for all six clusters, and the fraction of hours for which the $\mathrm{G}-\mathrm{R}$ correlation was $\geq 0.7$. The clusters are ordered from highest to lowest in terms of overall correlation [i.e., average of the (six) mean correlations]. For each cluster, the mean separation distance among the gauges and the mean range of the gauges from the radar also are shown.

From seeing the large portion of instances in which the fraction of hours with G-R correlation was $\geq 0.7$, indicating an explanation of $50 \%$ or more of the variance, it can be inferred that the radar did show appreciable skill, overall, in depicting the rainfall distribution over these very small, simulated stream networks (though for a substantial fraction of 
Table 2. Mean value of gauge-radar linear correlation coefficients within individual rain gauge clusters (subnetworks), averaged over multiple 1 - $\mathrm{h}$ events, and fraction of hours in which the gauge-radar correlation was $\geq 0.7$ for the Florida S-Pol dataset. The clusters are shown in order of highest to lowest mean correlation (averaged over all aggregation distances). Clusters TFB0101 and TFB0108 were $<40 \mathrm{~km}$ from the radar; SFL0010 and KSC0028 were between 50 and $70 \mathrm{~km}$ from the radar; and SFL0006 and SFL0031 were $>120 \mathrm{~km}$ from the radar. TFB0108 and TFB0101 had mean separation distances of their constituent gauges of $<1$ $\mathrm{km}$; for SFL0031 and SFL0010 this was between 1 and $1.5 \mathrm{~km}$, and for KSC0028 and SFL0006 this was $3 \mathrm{~km}$ or more.

\begin{tabular}{|c|c|c|c|c|c|c|c|}
\hline \multicolumn{8}{|c|}{ - Aggregation distance $(\mathrm{m})-$} \\
\hline \multicolumn{8}{|c|}{ Cluster KSC0028 ( 15 h; 3 or 4 gauges; mean separation 2.99 km; mean range 65.9 km) } \\
\hline & $\underline{150}$ & $\underline{300}$ & $\underline{450}$ & $\underline{600}$ & $\underline{750}$ & $\underline{900}$ & {$[\mathrm{Avg}$} \\
\hline mean correlation & 0.73 & 0.67 & 0.71 & 0.72 & 0.77 & $\mathbf{0 . 7 8}$ & {$[0.73]$} \\
\hline (fraction $\geq 0.7$ ) & $(0.67)$ & $(0.60)$ & $(0.67)$ & $(0.73)$ & $(0.80)$ & $(0.80)$ & \\
\hline \multicolumn{8}{|c|}{ Cluster SFL0010 (11 h; 4 gauges; mean separation 1.47 km; mean range 57.6 km) } \\
\hline & $\underline{150}$ & $\underline{\underline{300}}$ & $\underline{450}$ & $\underline{600}$ & $\underline{750}$ & $\underline{900}$ & [Avg] \\
\hline mean correlation & $\mathbf{0 . 5 8}$ & $\mathbf{0 . 6 9}$ & 0.67 & 0.63 & $\mathbf{0 . 7 0}$ & $\mathbf{0 . 6 0}$ & {$[0.64]$} \\
\hline$($ fraction $\geq 0.7)$ & $(0.73)$ & $(0.73)$ & $(0.64)$ & $(0.82)$ & $(0.82)$ & $(0.64)$ & \\
\hline \multicolumn{8}{|c|}{ Cluster TFB0101 (14 h; 5 to 7 gauges; mean separation $0.99 \mathrm{~km}$; mean range $36.8 \mathrm{~km}$ ) } \\
\hline & $\underline{150}$ & $\underline{300}$ & $\underline{450}$ & $\underline{600}$ & $\underline{750}$ & $\underline{900}$ & {$[\mathrm{Avg}]$} \\
\hline mean correlation & 0.60 & 0.62 & 0.62 & 0.66 & 0.62 & 0.66 & {$[0.63]$} \\
\hline (fraction $\geq 0.7$ ) & $(0.64)$ & $(0.64)$ & $(0.64)$ & $(0.79)$ & $(0.71)$ & $(0.71)$ & \\
\hline \multicolumn{8}{|c|}{ Cluster SFL0031 (19 h; 6 gauges; mean separation 1.04 km; mean range 143.2 km) } \\
\hline & $\underline{150}$ & $\underline{300}$ & $\underline{450}$ & $\underline{600}$ & $\underline{750}$ & $\underline{900}$ & [Avg] \\
\hline mean correlation & 0.49 & 0.48 & 0.49 & 0.49 & 0.55 & 0.48 & {$[0.50]$} \\
\hline (fraction $\geq 0.7$ ) & $(0.47)$ & $(0.42)$ & $(0.47)$ & $(0.53)$ & $(0.42)$ & $(0.53)$ & \\
\hline \multicolumn{8}{|c|}{ Cluster SFL0006 (18 h; 4 gauges; mean separation 3.53 km; mean range 129.4 km) } \\
\hline & $\underline{150}$ & $\underline{300}$ & $\underline{450}$ & $\underline{600}$ & $\underline{750}$ & $\underline{900}$ & [Avg] \\
\hline mean correlation & 0.50 & 0.43 & 0.47 & 0.47 & 0.50 & 0.48 & {$[0.48]$} \\
\hline (fraction $\geq 0.7$ ) & $(0.67)$ & $(0.61)$ & $(0.61)$ & $(0.67)$ & $(0.67)$ & $(0.67)$ & \\
\hline \multicolumn{8}{|c|}{ Cluster TFB0108 (14 h; 4 gauges; mean separation 0.76 km; mean range 38.1 km) } \\
\hline & $\underline{150}$ & $\underline{300}$ & $\underline{450}$ & $\underline{600}$ & $\underline{750}$ & $\underline{900}$ & {$[\mathrm{Avg}]$} \\
\hline mean correlation & 0.13 & 0.23 & $\mathbf{0 . 0 7}$ & $\mathbf{0 . 3 0}$ & $\mathbf{0 . 1 8}$ & $\mathbf{0 . 3 0}$ & {$[0.20]$} \\
\hline (fraction $\geq 0.7$ ) & $(0.14)$ & $(0.14)$ & $(0.14)$ & $(0.50)$ & $(0.21)$ & $(0.50)$ & \\
\hline
\end{tabular}

individual hours the correlation was near zero or negative). Within the individual clusters, there was perhaps a slight tendency toward better correlations at the larger aggregation distances $(\geq 600 \mathrm{~m})$ than the smaller ones $(\leq 450 \mathrm{~m})$. These variations, however, generally were small compared to the differences in average correlation from cluster to cluster, which ranged from a high of 0.73 to a low of 0.20 . We here examine whether these cluster-to-cluster variations may have been related to (i) the average separation distance of their constituent gauges or (ii) the mean range of those gauges from the radar, both of which varied widely.

The average G-R correlation of the ranked pairs is seen to be highest for networks with relatively medium-to-large average spacing between gauges (i.e., KSC0028 and SFL0010), whereas the network with the lowest average correlation, TFB0108, has the smallest mean separation distance. However, this tendency doesn't hold fully; the cluster with the second poorest overall correlation statistics, SFL006, has the highest mean gauge separation distance. With 
regard to the behavior of the clusters against distance from the radar, the $\mathrm{G}-\mathrm{R}$ correlations tend to be highest at the middle ranges (i.e., KSC0028 and SFL0010), whereas both closer (TFB0108) and farther (SFL006) from the radar the average correlations drop off somewhat. Thus, no clear tendencies are seen in the correlation characteristics of the clusters - considered as a whole - as a function of the proximity of their gauges to one another or the mean distance of their gauges from the radar.

Overall, then, the phase 2 assessment corroborated that of phase 1 (i.e., small and perhaps statistically insignificant differences being evident across the spatial aggregations for a given cluster, with perhaps some tendency toward slightly better results at the coarser resolutions). These differences within clusters, however, were overshadowed by the differences in mean performance between the clusters themselves.

\section{4) PHASE 3-G-R CORRELATION FOR SMALL- AREA HOURLY MEAN PRECIPITATION}

In the final phase of the experiment, gauge and radar values at each of the six aggregation levels were summed, individually, within the network clusters. These values approximate gauge and radar MAP, respectively, such as might be observed over small stream basins. Figure 8 provides a schematic representation of the rain gauge and radar sample bin aggregations used in this phase. Spatial aggregation might have some effect on radar MAPs because, with greater aggregation, precipitation immediately outside the area would be included.

Note that the two measures of MAP were considered to be the means of the discrete radar and gauge values, respectively, at the gauge points. No attempt was made to weigh the radar or gauge values as a function of their relative fractional coverage areas within the theoretical basins; that is, all gauges (and corresponding sample volumes) were weighted equally. Because the clusters are quite small, such weighting likely would have little effect on the outcome of the test.

Table 3 shows statistical results within these clusters, similarly as depicted in Table 1. Once again, the degree of radar spatial aggregation within each cluster generally has little, relative effect on the G-R MAP correlation or errors. Four of the six clusters, though, like SFL0010 and TFB0101, showed a tendency toward slightly smaller errors and standard deviations at their coarser resolutions, while two of

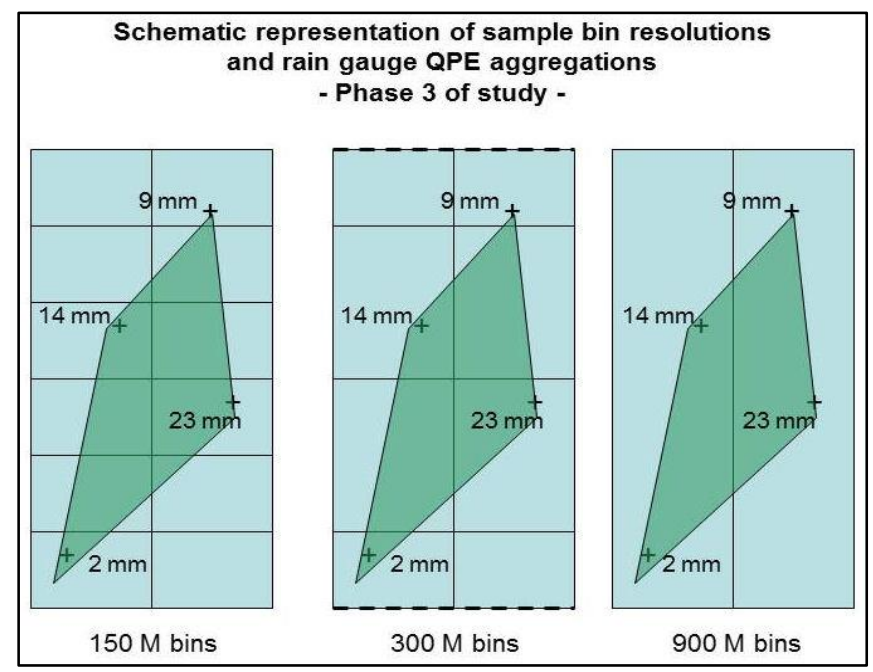

Figure 8. Schematic representation of radar sample bin QPE aggregations for phase 3 of the Florida S-Pol study: mean areal precipitation (MAP). Note that different radar sample bins contribute to the MAP of the (shaded) basin depending on which ones correspond to gauge points (i.e., four sample bins contribute to the MAP at 150-m resolution; four different, larger ones, contribute at $300 \mathrm{~m}$; two large ones contribute at $900 \mathrm{~m}$ ).

them, namely KSC0028 and TFB0108, revealed smaller errors at their finer resolutions. All showed very little variation in correlation coefficient across their aggregation levels.

\section{b) Oklahoma (KOUN-Oklahoma Mesonet) results}

For the Oklahoma portion of our study, described in section $4 \mathrm{~d}$ and undertaken to repeat the basic aspects of phase 1 of our Florida study, the statistical results for the $754 \mathrm{G}-\mathrm{R}$ pairs with nonzero precipitation are summarized in Table 4. Again, only very minor differences are seen in the various statistical measures across the aggregation levels (here 250, 500, 750 and $1000 \mathrm{~m}$ ), with just a slight trend in evidence toward smaller errors and standard deviations at the coarser resolutions.

These results, obtained from radar and rain gauge datasets geographically well-removed from Florida, tend to confirm our findings of there being scant differences across radar spatial-resolution levels.

\section{Discussion}

\section{a) Statistical significance determination}

In order to get a clearer picture of the degree of variation in results across the range of spatial aggregations and whether these differences would rank as statistically significant, we revisit phase 1 of our 
Table 3. Linear correlations and error measures between radar and gauge MAP estimates for the same clusters (subnetworks) as in Table 2. Statistical measures same as in Table 1.

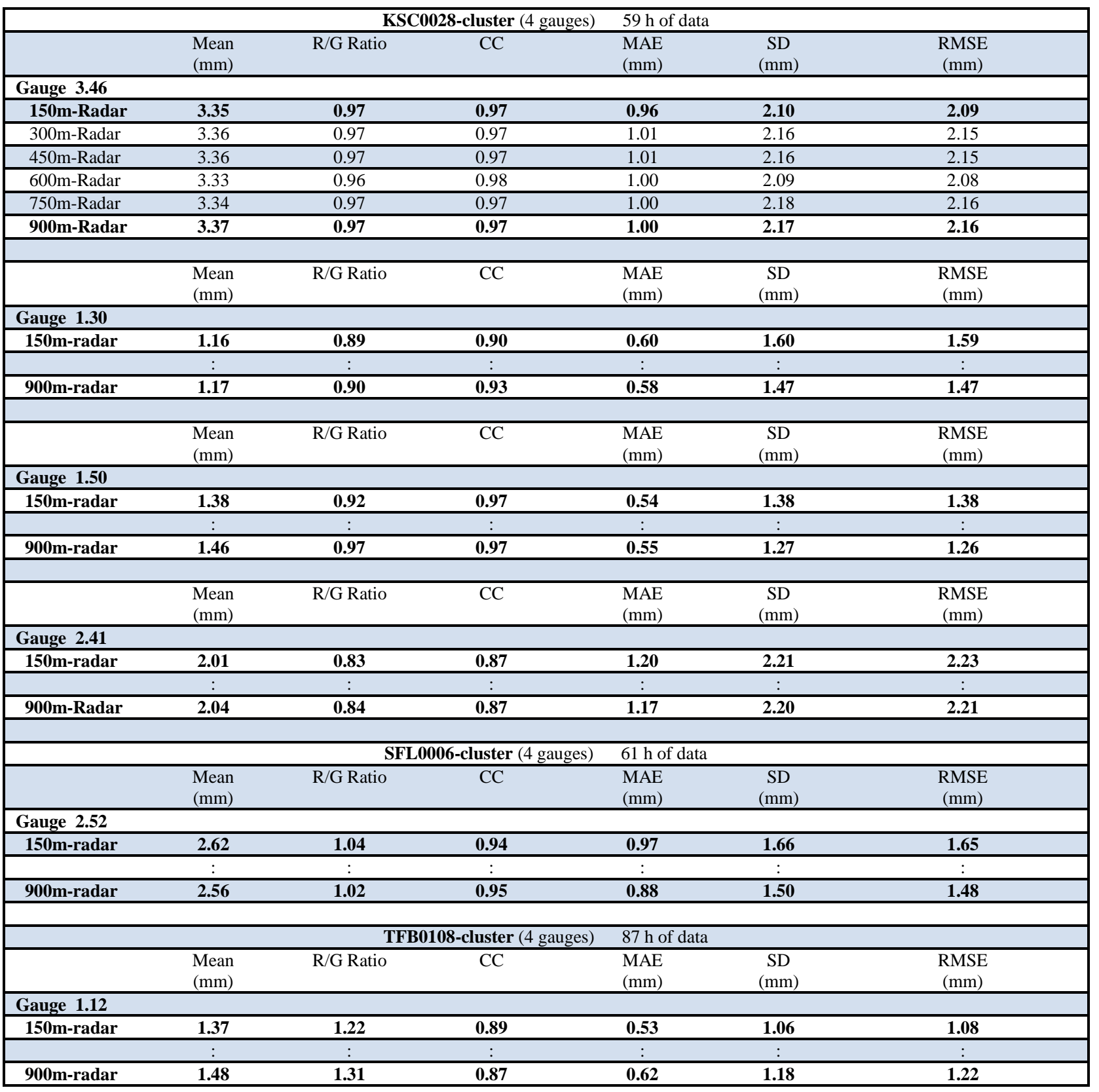

Table 4. As in Table 1, except statistics for 754 gauge/radar pairs over Oklahoma collected during storm events in 2004 and 2005.

\begin{tabular}{|c|c|c|c|c|c|c|}
\hline All ranges: & 754 R/G-da & gauge mean & & & & \\
\hline Radar & Mean (mm) & R/G Ratio & $\mathrm{CC}$ & MAE (mm) & SD (mm) & RMSE (mm) \\
\hline 250m-res & 3.36 & 1.00 & 0.80 & 1.77 & 3.20 & 3.66 \\
\hline 500m-res & 3.37 & 1.00 & 0.80 & 1.75 & 3.18 & 3.63 \\
\hline 750m-res & 3.39 & 1.01 & 0.81 & 1.76 & 3.15 & 3.61 \\
\hline 1000 m-res & 3.39 & 1.01 & 0.81 & 1.75 & 3.11 & 3.57 \\
\hline
\end{tabular}


Florida study with a focus placed on just the finest $(150 \mathrm{~m})$ and coarsest $(900 \mathrm{~m})$ radar resolutions. We also now further break down the results as a function of precipitation rate into three categories: all nonzero $(\geq 0.1 \mathrm{~mm})$; moderate-and-above $\left(\geq 10.0 \mathrm{~mm} \mathrm{~h}^{-1}\right)$; and heavy $\left(\geq 25.4 \mathrm{~mm} \mathrm{~h}^{-1}\right)$.

Figures 9 and 10 depict the hourly G-R CC and MAE, respectively, in bar diagram format at the 150$\mathrm{m}$ and $900-\mathrm{m}$ resolutions at the near $(0-67 \mathrm{~km})$, middle $(67-106 \mathrm{~km})$, and far $(106-171 \mathrm{~km})$ range bands, as well as for all ranges combined for all nonzero G-R pairs. It is seen that for both these fields, slightly better results (i.e., higher CC and lower MAE) are found at $150-\mathrm{m}$ resolution at the near- and middleranges, while slightly better results are found at $900-\mathrm{m}$ resolution at the far range. For all ranges combined, the results for both $\mathrm{CC}$ and MAE are virtually indistinguishable.

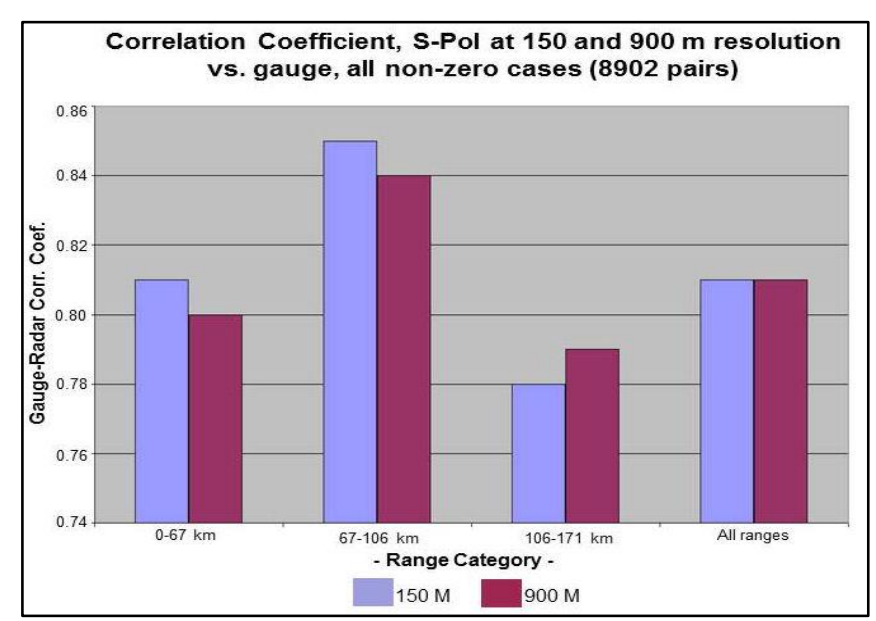

Figure 9. Correlation coefficient for all Florida S-Pol nonzero cases during June-August 1998 in ranges (a) near (0-67 km), (b) middle $(67-106 \mathrm{~km}),(\mathrm{c})$ far (106-171 km), and (d) all combined. The number of pairs used in each comparison are displayed below the $x$-axis.

Figures 11 and 12 depict the same as Figs. 9 and 10 , but only for moderate-and-above precipitation rates, while Figs. 13 and 14 depict the same for heavyonly precipitation rates. It is seen that for the moderate-and-above cases, the results are almost identical to those for all precipitation rates, while for the heavy-only cases, slightly better results are found in all range bands at the coarsest $(900 \mathrm{~m})$ resolution. However, correlation coefficients are virtually zero, or even negative, within the near- and far-range bands, respectively, which may be a consequence of the relatively small number of samples in the sample set (affecting the stability of the correlation).

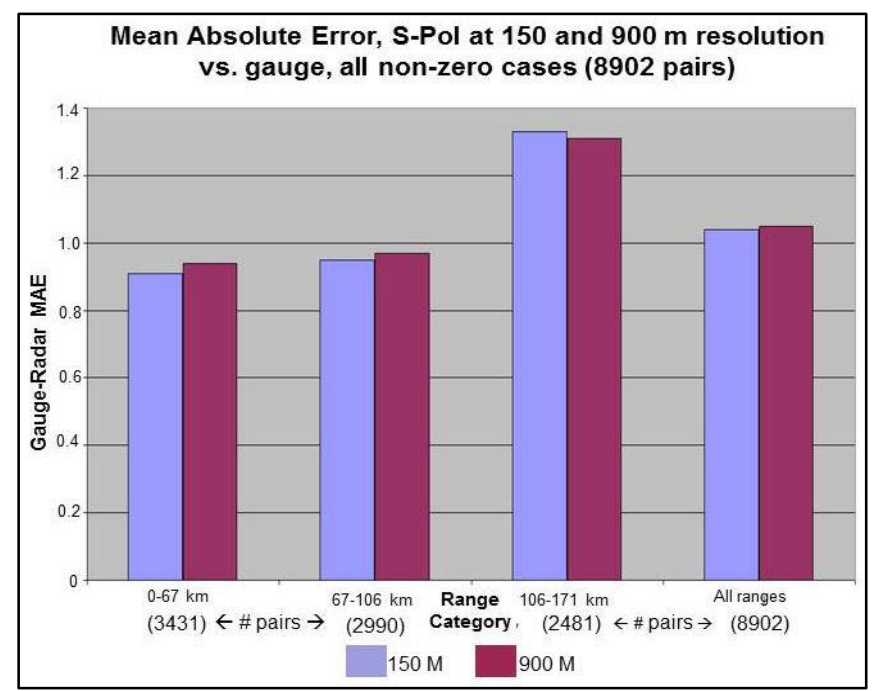

Figure 10. Same as Fig. 9 except for mean absolute error.

\section{b) Application of permutation tests on the mean absolute error fields}

In order to determine whether these generally small differences between the 150- and 900-m radar aggregations have any statistical and/or practical significance, it is necessary to test the hypothesis that the two sets of estimates are actually the same, and that the differences are due to chance. We did this for the MAE fields across all the range groupings and intensity levels in phase 1, as shown in Figs. 10, 12, and 14 , as well as for situations such as the difference (gradient) between the largest and smallest radar aggregations being at least $2.5 \mathrm{~mm}$, as explained in phase 2 (above). A total of 16 combinations of the various threshold precipitation rates and range bands were tested.

For our statistical significance determination, we employed a permutation or recombination method similar to that of a Fisher's permutation test (as advised by a subject matter expert-K. Elmore 2012, personal communication). This approach has the advantage that it does not depend on any assumptions about the distribution of the samples. The method (as illustrated in Nichols and Holmes 2002) relies on pooling all the absolute error values from both the $150-\mathrm{m}$ and $900-\mathrm{m}$ resolutions into a single sample, which is then re-divided into two equal-sized subsamples at random, numerous times. Each time, the means of the two subsamples are calculated and the difference in the sample means recorded. The procedure results in a distribution of difference values arising solely by chance. If our original 150-900-m difference in means is within the 5th-to-95th percentile 


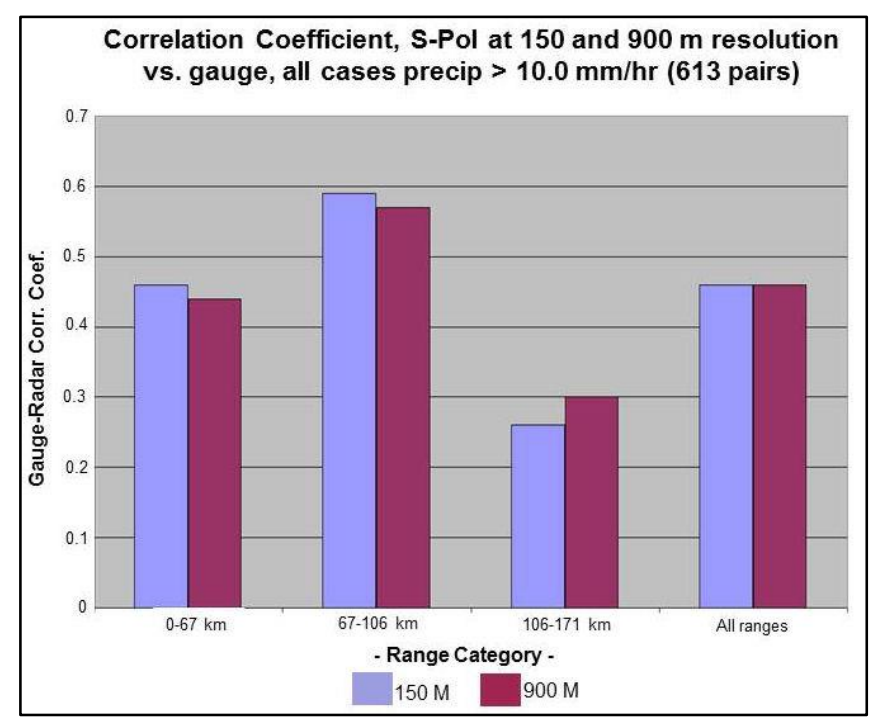

Figure 11. Correlation coefficient for all Florida S-Pol moderateand-greater hourly cases during June-August 1998; otherwise same as in Fig 9.

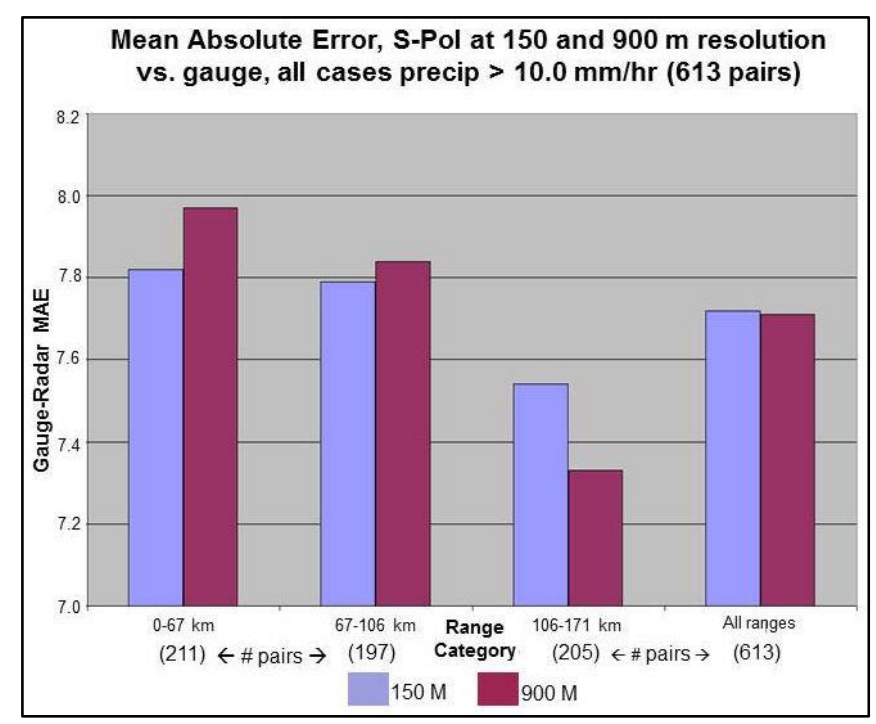

Figure 12. Mean absolute error for all Florida S-Pol moderate-andgreater hourly cases during June-August 1998; otherwise same as in Fig 10.

range of this distribution, we conclude that our difference is not statistically significant at the twotailed, $5 \%$ confidence level.

For example, we found that within the sample of all 8902 Florida precipitation cases, the 150- and 900$\mathrm{m}$ resolution estimates had MAE values of $1.154 \mathrm{~mm}$ and $1.166 \mathrm{~mm}$, respectively; the difference was thus $-0.012 \mathrm{~mm}$. After pooling both sets of absolute error values into a single set of 17804 cases, pairs of samples of the 8902 elements each were drawn at random from the pool, without replacement, 5000

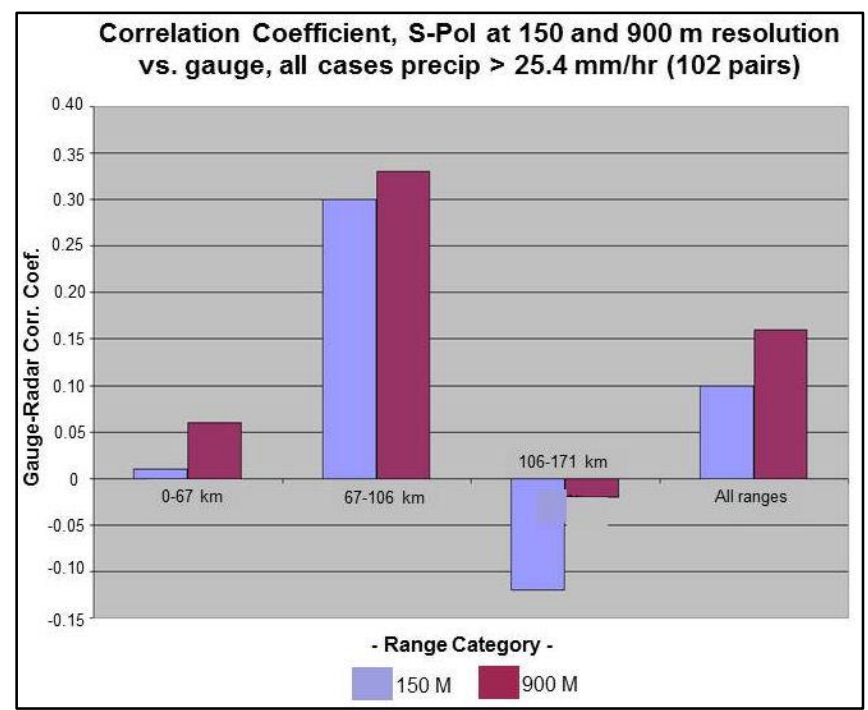

Figure 13. Correlation coefficient for all Florida S-Pol heavy hourly rainfall cases during June-August 1998; otherwise same as in Fig 9.

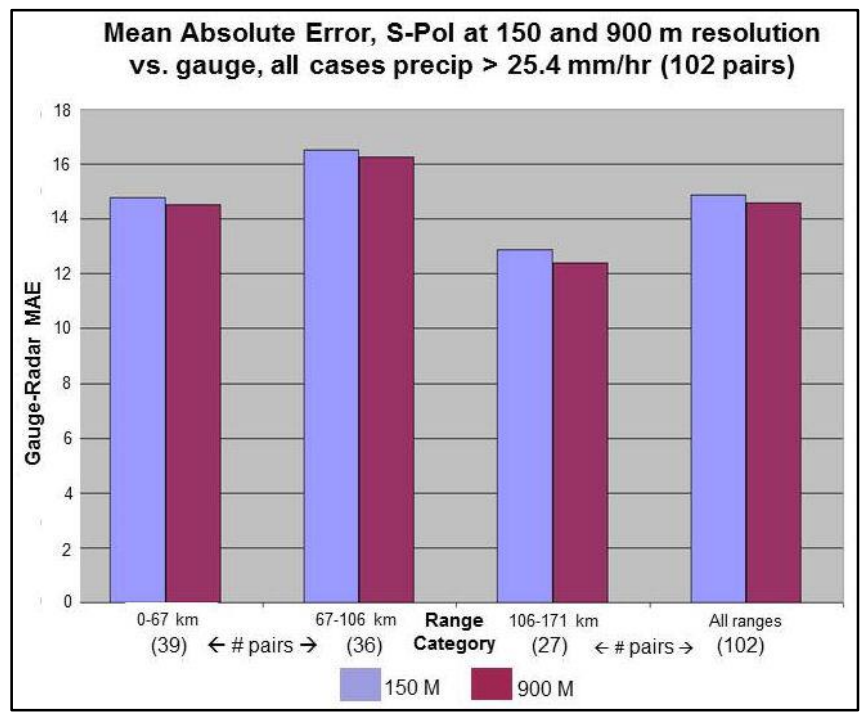

Figure 14. Mean absolute error for all Florida S-Pol heavy hourly rainfall cases during June-August 1998; otherwise same as in Fig 10 .

times. We found that the 5th and 95th percentile values of that set of differences were $-0.067 \mathrm{~mm}$ and $+0.068 \mathrm{~mm}$, respectively. Because our 150-900-m difference $(-0.012 \mathrm{~mm})$ fell well within this range, we conclude that there is at least a $10 \%$ chance-and probably much greater - that this difference could have come from random variations within a sample set, and hence, the radar data resolution had no effect on observation accuracy.

In this and all other instances tested, we likewise found the differences between the lowest and highest 
aggregation levels to be not statistically significant. Results for some of the situations highlighted in Figs. 10, 12, and 14 are shown in Table 5.

\section{c) Possible effects of time discretization on radar QPE errors}

Our principal finding-that substantially higher spatial resolution in radar input to QPE fields at the scales and intervals used in NWS operations would have little influence on the accuracy of those estimates - is likely due to multiple factors. These include errors in estimating the rates themselves, atmospheric effects on falling hydrometeors, high spatial correlation of light precipitation that renders high-resolution observations redundant, and time discretization errors that become apparent when there are large changes in precipitation rate over time at any one point. To some extent, time discretization errors can be visualized graphically, and because it might be possible to mitigate these error effects even in existing data, we will explore this error source.

Table 5. As in Table 1, except statistics for 754 gauge/radar pairs over Oklahoma collected during storm events in 2004 and 2005.

\begin{tabular}{|c|c|c|c|c|c|}
\hline $\begin{array}{c}\text { Min precip } \\
\text { rate (mm) }\end{array}$ & $\begin{array}{c}\text { Range from } \\
\text { radar (km) }\end{array}$ & $\begin{array}{c}\text { Experimental MAE } \\
\text { diff. (mm) }\end{array}$ & $\begin{array}{c}\text { Number of } \\
\text { cases }\end{array}$ & 5th-95th percentile range (mm) & Within range? \\
\hline$\geq 0$ & all & -0.014 & 8902 & -0.067 to +0.068 & Y \\
\hline$\geq 10$ & all & +0.002 & 613 & -0.633 to +0.633 & Y \\
\hline$\geq 25.4$ & all & +0.307 & 102 & -2.516 to +2.572 & Y \\
\hline$\geq 0$ & $<67$ & -0.035 & 3431 & -0.105 to +0.108 & Y \\
\hline$\geq 0$ & $67-106$ & -0.018 & 2990 & -0.118 to +0.117 & Y \\
\hline$\geq 0$ & $>106$ & +0.018 & 2481 & -0.131 to +0.124 & $\mathrm{Y}$ \\
\hline
\end{tabular}

Even though considerable effort has been expended to improve radar estimates of instantaneous precipitation rates - for example, the implementation of DP capability-treatment of radar temporal estimation has lagged. That is, radar QPEs at any one place are based on a set of near-instantaneous rates, separated by several minutes. A common, inherent assumption - including that used in the WSR-88D-is that at any one place the precipitation rates vary linearly in time. While this is an adequate assumption in lighter or stratiform rainfall, heavy convective rainfall cannot be modeled with this simple approach.

An example of the errors due to time discretization effects is shown in Fig. 15, adapted from Smith et al. (2009). A time series of 1-min precipitation rates was collected by a disdrometer during heavy rain events. Very large minute-to-minute variations are evident. Based on the continuous series of rate measurements, the precipitation total for the 20 -min event is $12.7 \mathrm{~mm}$.

If a sensing system were to collect observations over the disdrometer at 5-min intervals, as many surveillance radars do, and only linear time variation was assumed between observations, we would obtain accumulation estimates varying from 9.8 to $16.4 \mathrm{~mm}$, depending on the starting time and which ensuing minutes were sampled. These correspond to observation series indicated by points B (dotted line) and A (dashed line), respectively. Note that this exercise neglects any errors in the estimates themselves.

Because radar sampling volumes are rather large, even close to the radar, the QPEs do not represent truly instantaneous rates as would be observed at a point on the ground surface. First, it takes some time for all hydrometeors to drop from the radar sampling volume. Second, the horizontal averaging implicit in the radar data collection partially accounts for small-scale spatial variations in the rain rate pattern, and for the movement of the pattern between volume scans. Therefore, we can expect that some limited degree of spatial smoothing in the radar estimates mitigates errors that arise as a consequence of the very limited temporal sampling necessitated by volumetric surveillance scanning.

Time discretization errors on radar accumulations often are seen clearly in cases with small, intense, rapidly moving cells. As shown in Fig. 16, nonzero or heavier spots of precipitation appear at the location of the cells at the times when the radar scanned them; zero or smaller amounts are shown for the places traversed by the cells between volume scans. The effects of time discretization become most serious in situations of heavy precipitation and small spatial sampling volumes; at the extreme, the assumption of 


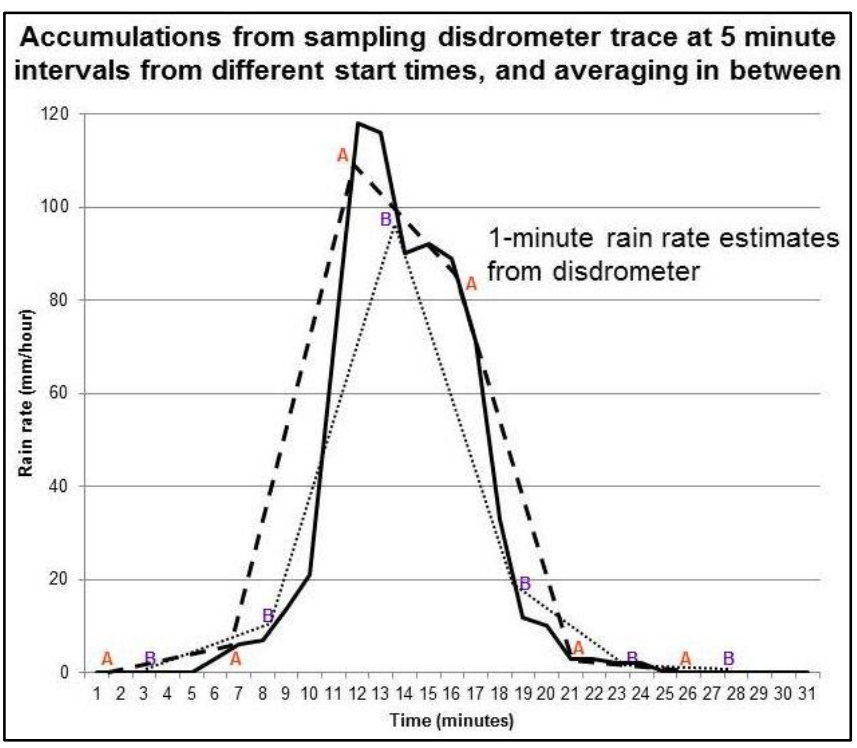

Figure 15. 1-min precipitation rates from a disdrometer (after Smith et al. 2009), illustrating rapid, nonlinear changes in rainfall rate. Total for the event is estimated at $12.7 \mathrm{~mm}$. Sampling at 5min and assuming linear variation of rainfall rate in time results in estimates of $16.4 \mathrm{~mm}$ (red points $\mathrm{A}$, dashed line) and $9.8 \mathrm{~mm}$ (purple points B, dotted line).

linear time variation of precipitation rates yields a patchwork of under- and over-estimates that clearly appears unrealistic.

Because we followed the common approach of assuming linear variation in rainfall rate between radar scans, our findings were subject to time discretization errors. Smaller radar sample volumes might provide a better representation of the instantaneous rate field, but in situations with large spatial-temporal gradients in rainfall rate, the time integration technique would be inadequate. It should be possible to mitigate these discretization errors by using common pattern-tracking algorithms to extrapolate the precipitation pattern in space, so as to simulate the system movement between volume scans. This morphing technique is one that presently is applied, operationally, to satellite precipitation rate estimates, which might be collected at intervals of several hours (Joyce et al. 2004). In the future, radar QPE errors also could be mitigated through alternative scanning strategies (Chrisman 2009) and the implementation of phased-array radar technology (Heinselman and Torres 2011).

\section{Summary and conclusions}

In order to determine whether NWS operational radar-reflectivity data that have recently become available at substantially higher spatial resolution

\section{Sample 1-hr accumulation product showing "morphing"} phenomenon due to rapid cell movement and infrequent sampling
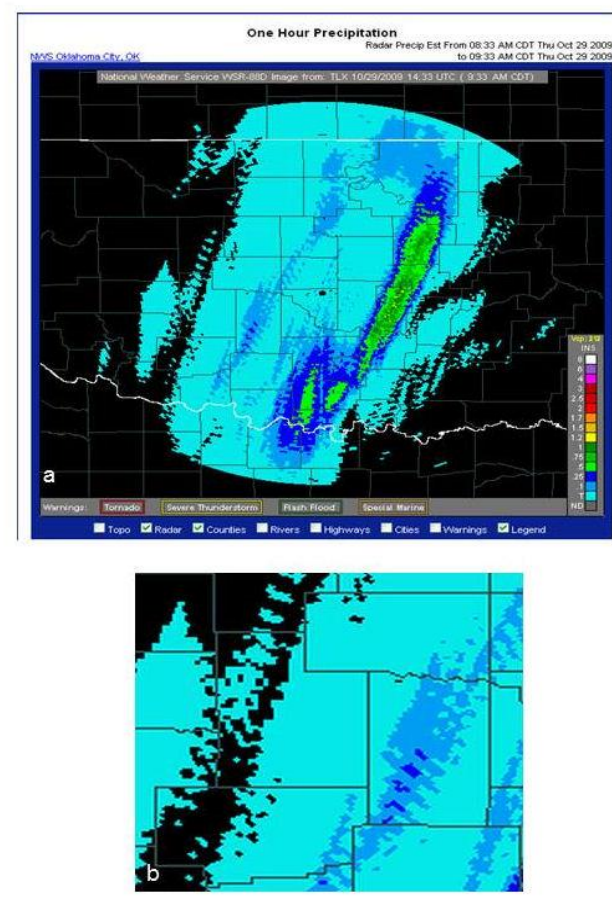

Figure 16. a) 1-h precipitation ending 1433 UTC 29 October 2009, from the Twin Lakes, OK, WSR-88D. Scaling pattern is due to small precipitation cells that moved several sampling pixels between volumetric scans, coupled with an assumption of linear variation in precipitation rate with time at any one point. b) Enlargement of (a) to show morphing phenomenon.

(though not at higher temporal resolution) may yield increased accuracy in rainfall estimates when distributed over small basins, we performed G-R statistical evaluations at resolutions ranging from the new (finer) to the legacy (coarser). We did this on a total of over 9500 samples from two paired datasets: one in Florida and one in Oklahoma. The radar QPEs were determined from single-polarization, S-band data in the manner of the WSR-88D legacy PPS. On the more extensive Florida dataset, we evaluated the data in ranked-pair and MAP configurations in simulated basins, in addition to performing a more straightforward evaluation on all the nonzero, hourly $\mathrm{G}-\mathrm{R}$ pairs under the radar umbrella, which we then further broke down into range bands (near, middle, and far) and by rainfall intensity (all intensities, moderate-andabove, and heavy).

In the assessments performed at these various configurations, we generally found little appreciable difference among the G-R statistics across the range of radar spatial resolutions. In some instances, such as at near and middle ranges in phase 1 of the Florida 
study, a minor tendency toward better results at the finer resolutions was observed, while in others, such as at far ranges and in phases 2 and 3 of the Florida study as well as in the Oklahoma study, a slight tendency toward better results at the coarser resolutions was in evidence. However, when we performed numerous iterations of a permutation test on the differences in MAEs between the finest and coarsest resolutions, we found those differences to be not statistically significant in all circumstances evaluated.

These results indicate that hoped-for benefits in better QPE from WSR-88D systems from sampling at finer spatial resolution, alone, have not yet been realized, and high-resolution hydrologic models cannot be expected to perform better, overall, as a consequence of more accurate allocation of precipitation into delineated stream basins. Benefits may be achievable, however, with commensurate increases in sampling frequency, and/or by employing extrapolation techniques to estimate precipitation rates between volume scans.

Acknowledgments. We are indebted to Scott Ellis and the NCAR staff for assistance with obtaining and interpreting the 1998 Florida S-Pol radar data; corresponding rain gauge reports were obtained from the TRMM SVO. Oklahoma radar data from 2004 through 2005 were provided by the National Severe Storms Laboratory (John Krause and Kevin Scharfenberg) and matching gauge data by the Oklahoma Climate Survey. We received valuable assistance in the interpretation of statistical significance from Jim Ward (OHD/HL - WYLE Info. Systems, LLC) and Kim Elmore (OAR/NSSL).

\section{REFERENCES}

Brandes, E. A., J. Vivekanandan, and J. W. Wilson, 1999: A comparison of radar reflectivity estimates of rainfall from collocated radars. J. Atmos. Oceanic Technol., 16, 12641272.

Brown, R. A., B. A. Flickinger, E. Forren, D. M. Schultz, D. Sirmans, P. L. Spencer, V. T. Wood, and C. L. Ziegler, 2005: Improved detection of severe storms using experimental fine-resolution WSR-88D measurements. Wea. Forecasting, 20, 3-14.

Chrisman, J. N., 2009: Automated Volume Scan Evaluation and Termination (AVSET): A simple technique to achieve faster volume scan updates. Preprints, 34th Conf. on Radar Meteorology, Williamsburg, VA, Amer. Meteor. Soc., P4.4. [Available online at ams.confex.com/ams/pdfpapers/ 155324.pdf].

Corbert, J. H., 1974: Physical Geography Manual. 5th ed. Kendall Hunt, 127 pp.
Fulton, R. A, J. P. Breidenbach, D.-J. Seo, D. A. Miller, and T. O'Bannon, 1998: The WSR-88D rainfall algorithm. Wea. Forecasting, 13, 377-395.

Gebremichael, M., and W. F. Krajewski, 2004: Assessment of the statistical characterization of small-scale rainfall variability from radar: Analysis of TRMM ground validation datasets. J. Appl. Meteor., 43, 1180-1199.

Habib, E., and W. F. Krajewski, 2002: Uncertainty analysis of the TRMM ground-validation radar-rainfall products: Application to the TEFLUN-B field campaign. J. Appl. Meteor., 41, 558-572.

Heinselman, P. L., and S. M. Torres, 2011: High-temporalresolution capabilities of the National Weather Radar Testbed Phased-Array Radar. J. Appl. Meteor. Climatol., 50, 579-593.

Joyce, R. J., J. E. Janowiak, P. A. Arkin, and P. Xie, 2004: CMORPH: A method that produces global precipitation estimates from passive microwave and infrared data at high spatial and temporal resolution. J. Hydrometeor., 5, 487-503.

Kitzmiller, D., D. Miller, R. Fulton, and F. Ding, 2013: Radar and multisensor precipitation estimation techniques in National Weather Service hydrologic operations. J. Hydrol. Eng., 18, 133-142.

Knox, R., and E. Anagnostou, 2009: Scale interactions in radar rainfall estimation uncertainty. J. Hydrol. Eng., 14, 944953.

McPherson, R. A., and Coauthors, 2007: Statewide monitoring of the mesoscale environment: A technical update on the Oklahoma Mesonet. J. Atmos. Oceanic Technol., 24, 301321 .

Nichols, T. E., and A. P. Holmes, 2002: Nonparametric permutation tests for functional neuroimaging: A primer with examples. Hum. Brain Mapp., 15, 1-25.

Park, H. S., A. V. Ryzhkov, D. S. Zrnić, and K.-E. Kim, 2009: The hydrometeor classification algorithm for the polarimetric WSR-88D: Description and application to an MCS. Wea. Forecasting, 24, 730-748.

Ryzhkov, A. V., S. E. Giangrande, and T. J. Schuur, 2005: Rainfall estimation with a polarimetric prototype of WSR88D. J. Appl. Meteor., 44, 502-515.

Seo, B.-C., and W. F. Krajewski, 2010: Scale dependence of radar rainfall uncertainty: Initial evaluation of NEXRAD's new super-resolution data for hydrologic applications. $J$. Hydrometeor, 11, 1191-1198.

Smith, J. A., E. Hui, M. Steiner, M. L. Baeck, W. F. Krajewski, and A. A. Ntelekos, 2009: Variability of rainfall rate and raindrop size distributions in heavy rain. Water Resour. Res., 45, W04430. doi:10.1029/ 2008WR006840.

Torres, S., and C. D. Curtis, 2006: Design considerations for improved tornado detection using super-resolution data on the NEXRAD network. Preprints, Fourth European Conf. on Radar Meteorology and Hydrology (ERAD), Barcelona, Spain, Copernicus.

Wang, J., and D. B. Wolff, 2010: Evaluation of TRMM ground-validation radar-rain errors using rain gauge measurements. J. Appl. Meteor. Climatol., 49, 310-324. 